\title{
Characteristics of foreshock activity inferred from the JMA earthquake catalog
}

\author{
Koji Tamaribuchi ${ }^{* *} \mathbb{0}$, Yuji Yagi $^{2}$, Bogdan Enescu ${ }^{3}$ and Shiro Hirano ${ }^{4}$
}

\begin{abstract}
We investigated the foreshock activity characteristics using the Japan Meteorological Agency Unified Earthquake Catalog for the last 20 years. Using the nearest-neighbor distance approach, we systematically and objectively classified the earthquakes into clustered and background seismicity. We further categorized the clustered events into foreshocks, mainshocks, and aftershocks and analyzed their statistical features such as the $b$-value of the frequency-magnitude distribution. We found that the $b$-values of the foreshocks are lower than those of the aftershocks. This $b$-value difference suggested that not only the stochastic cascade effect but also the stress changes/aseismic processes may contribute to the mainshock-triggering process. However, forecasting the mainshock based on $b$-value analysis may be difficult. In addition, the rate of foreshock occurrence in all clusters (with two or more events) was nearly constant (30-40\%) over a wide magnitude range. The difference in the magnitude, time, and epicentral distance between the mainshock and largest foreshock followed a power law. We inferred that the distinctive characteristics of foreshocks can be better revealed using the improved catalog, which includes the micro-earthquake information.
\end{abstract}

Keywords: Foreshocks, Aftershocks, b-value, Nearest-neighbor distance, JMA unified catalog

\section{Introduction}

Foreshocks are earthquakes that occur prior to the mainshock, which is defined as the largest magnitude event in an earthquake sequence. The foreshock activity often shows significant differences compared with the ordinary seismic activity such as a decreased $b$-value (e.g., Suyehiro 1966; Enescu and Ito 2001; Nanjo et al. 2012; Tormann et al. 2015) and migration and acceleration prior to the mainshock (e.g., Kato et al. 2012; Marsan et al. 2014). While these foreshock characteristics may reflect the accumulation of stress and/or the occurrence of slow slip within the seismogenic zone, Helmstetter et al. (2003) showed that such features may also be explained by simply using the ETAS statistical model of seismicity (Ogata 1988) and Gutenberg-Richter law (G-R law). Thus, they may reflect stochastic rather than physical processes.

Two recent large earthquakes, the 2011 M9.0 earthquake off the Pacific coast of Tohoku (Tohoku-oki) and the 2016 M7.3 Kumamoto earthquakes, were

*Correspondence: ktamarib@mri-jma.go.jp

${ }^{1}$ Meteorological Research Institute, Japan Meteorological Agency,

Tsukuba, Japan

Full list of author information is available at the end of the article accompanied by M6-7 foreshock activities (e.g., Kato et al. 2012, 2016; Marsan and Enescu 2012). For the case of the 2016 Kumamoto sequence, the Japan Meteorological Agency (JMA) issued aftershock probabilities following the April 14 M6.5 earthquake based on the Earthquake Research Committee (ERC) protocol (ERC 1998, 2016). However, a larger earthquake, the M7.3 Kumamoto Earthquake (the mainshock), occurred on April 16. This case illustrates that it is impossible to determine whether an earthquake is a foreshock before the occurrence of the mainshock. However, by statistically analyzing past foreshock sequences, researchers have attempted to probabilistically forecast the occurrence of a larger event, the mainshock (Jones 1985; Abercrombie and Mori 1996; Maeda 1996; Reasenberg 1999; Ogata and Katsura 2012). In many of these studies, relatively large magnitude thresholds were used, for example, $M \geq 4$ (Ogata and Katsura 2012), due to the incomplete detection of smaller events. Because the foreshock activity has a wide range of magnitudes and diverse patterns, it is important to detect smaller events and potentially reveal foreshock patterns over a wide magnitude 
range (such as M0-6) to understand the foreshock characteristics.

The JMA published and routinely updates an earthquake catalog (JMA unified catalog) in cooperation with the Ministry of Education, Culture, Sports, Science and Technology (MEXT) using seismic waveforms of stations belonging to the JMA, National Research Institute for Earth Science and Disaster Resilience (NIED), universities, and other institutes. The publication of the JMA unified catalog started in October 1997, and the data have been archived for approximately 20 years. Figure 1 shows the number of events in the catalog from October 1997 to July 2017. The number of detected events increased since 2000 due to the deployment of the Hi-net NIED network (Okada et al. 2004). However, $M \geq 1$ earthquakes have been recorded constantly. Visual inspection of all events was impossible after the 2011 Tohoku-oki Earthquake because a large number of earthquakes occurred in Japan, even in inland areas such as the northern part of the Ibaraki Prefecture. Therefore, the $M<2$ earthquakes have not been completely cataloged in the aftershocks area of the 2011 Tohoku-oki Earthquake. In April 2016, the JMA adopted a new automatic processing methodology, developed by Tamaribuchi et al. (2016) to more accurately and quickly determine small earthquakes; thus, the number of $M<1$ quakes significantly increased (Fig. 1b; see details in JMA, 2017). In this study, we report the characteristics of foreshocks and aftershocks over a wide magnitude range using a long-term interval (1997-2017).

\section{Data and method}

We used the JMA unified catalog and targeted the shallow (depth $\leq 30 \mathrm{~km}$ ) inland seismicity in Japan, which has a near-homogeneous completeness magnitude of approximately 1.0 (e.g., Nanjo et al. 2010). Note that we estimated the magnitude of completeness before determining (and discussing) the $b$-values of foreshocks and aftershocks to avoid any possible bias, as explained in detail at the end of this section. The data span over the period from October 1, 1997, to July 25, $2017(M \geq 1$; long-term period). We also investigated the period from April 1, 2016, to July 25, 2017 ( $M \geq 0$; short-term period) to confirm the effect of the improvement of the JMA unified catalog by automatic processing (Tamaribuchi et al. 2016). This automatic processing method determines the hypocenters of earthquakes that occur simultaneously by searching for the optimal combination of P- and S-wave arrival times and maximum amplitudes using a Bayesian estimation technique. The system detects nearly twice as many earthquakes as those listed in the conventional JMA catalog. By effectively using this catalog, the seismic activity can be investigated over a wide magnitude range.

First, we clustered the seismic activity to extract foreshocks and aftershocks from numerous hypocenters. Several automatic clustering methods have already been proposed (e.g., Frohlich and Davis 1990; Ogata and Katsura 2014), which are suitable for the analysis of big datasets. In this study, we used the nearest-neighbor distance method (Baiesi and Paczuski 2004; Zaliapin and BenZion 2013), which can clearly and objectively distinguish the clustered and background earthquakes. We used a

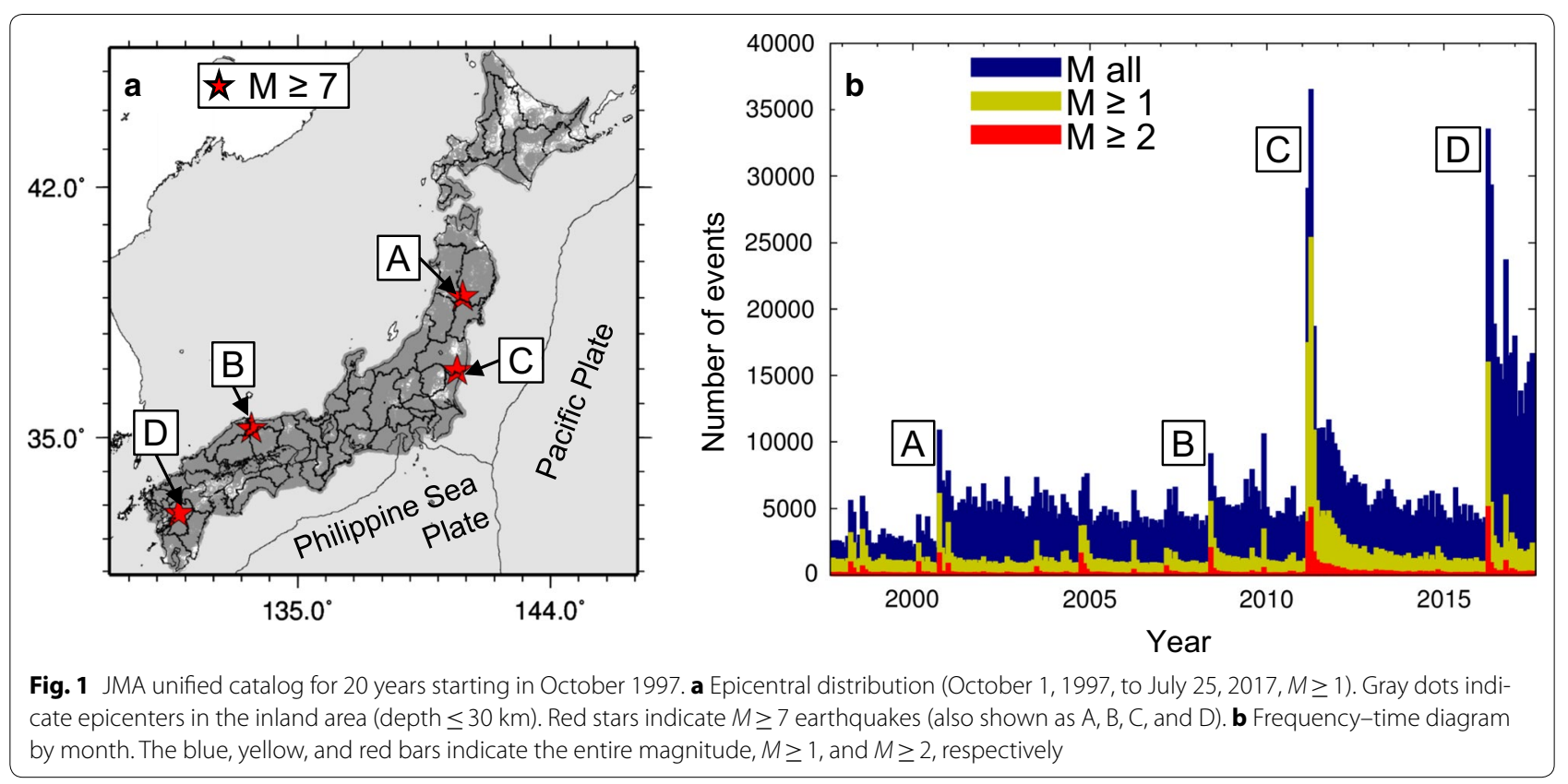


program by Kasahara (2016) for the analysis, which is faster than the general implementation [the calculation cost is reduced from $O\left(N^{2}\right)$ to $\left.O(N \sqrt{N})\right]$ and allows the method to be applied to large earthquake catalogs. The seismic activity was clustered by defining a new metric (called "distance") between events and determined using the epicentral distance, time difference between event pairs, and magnitude information. The new metric is defined by the following equation:

$$
\begin{cases}\eta_{i j}=t_{i j}\left(r_{i j}\right)^{d_{f}} 10^{-b m_{i}}, & t_{i j}>0 \\ \eta_{i j}=\infty, & t_{i j} \leq 0 .\end{cases}
$$

The parameter, $\eta_{i j}$, is the distance between the events, $i$ and $j ; t_{i j}$ is the difference in the origin time (year); $r_{i j}$ is the epicentral distance $(\mathrm{km}) ; m_{i}$ is the magnitude of the parent event, $i ; d_{f}$ and $b$ are the fractal dimensions of the epicentral distributions of earthquakes and $b$-value, respectively. By dividing the aforementioned equation into time and spatial components, that is, $T_{i j}=t_{i j} 10^{-q b m_{i}}$ and $R_{i j}=\left(r_{i j}\right)^{d_{f}} 10^{-(1-q) b m_{i}}$, respectively, we can also describe Eq. (1) as $\eta_{i j}=T_{i j} R_{i j}$. $q$ is a free parameter. Each parameter was set by following Zaliapin and Ben-Zion (2013), that is, $d_{f}=1.6, b=1.0$, and $q=0.5$. Based on this algorithm, the distance, $\eta_{i j}$, was calculated for each event, $j$, and the shortest distance, $\eta_{i j}$, between the parent event, $i$, and the child event, $j$, was taken as the nearest-neighbor distance.

Second, based on Zaliapin and Ben-Zion (2013), we defined a threshold, $\eta_{0}$, that distinguishes whether two events are strongly or weakly linked. In other words, in the case of $\eta<\eta_{0}$, the event pair is strongly linked (clustered), while the event pair is weakly linked in the case of $\eta \geq \eta_{0}$. (The events may belong to background seismicity.) Weakly linked events are well described by a Poisson (random) process. The histogram of $\eta$ was fitted assuming two mixed Weibull distributions for the strongly and weakly linked seismicity (Fig. 2a, b). The threshold, $\eta_{0}$, is defined as the intersection of the two fitted distributions. By sequentially linking strongly related pairs, we can build clusters of events. For each cluster, we defined the foreshocks, mainshock, and aftershocks in the same way as in conventional studies. The mainshock is defined as the earthquake of largest magnitude in each cluster, while the foreshocks and aftershocks are earthquakes occurring before and after the mainshock, respectively. If there are two or more earthquakes of the same largest magnitude, the one that occurred earlier is considered to be the mainshock. Events with $\eta \geq \eta_{0}$ that have no child events are referred as singles. Clusters that have a mainshock, foreshocks, and/or aftershocks are referred as families; that is, one "family" has two or more events in contrast to a "single," which comprises one event.
We estimated the $b$-values of the clusters using the maximum likelihood method (Aki 1965; Utsu 1965). To calculate the standard error of the $b$-values, $\sigma_{b}$, we used the equation of Shi and Bolt (1982). We determined the completeness magnitude, Mc, based on the "MAXC" approach, proposed by Wiemer and Wyss (2000), which considers the highest frequency of events in the noncumulative frequency-magnitude distribution. The magnitude of completeness is defined as MAXC +0.2 according to Woessner and Wiemer (2005). When $b$-values for different distributions are compared, Mc is first calculated for each dataset, and the largest value is used as the magnitude threshold.

\section{Results}

Figure 2c, d shows the histogram of the nearest-neighbor distance, $\eta$, between earthquakes based on short-term data; the long-term data are also shown in Fig. 2e, f. The histogram of both datasets shows a bimodal distribution. The threshold for the long-term data, $\log \left(\eta_{0}\right)=-4.2$, is slightly larger than the threshold of Zaliapin and BenZion (2013) of $\log \left(\eta_{0}\right)=-5.0$. This trend was also observed for the short-term data $\left(\log \left(\eta_{0}\right)=-4.5\right)$. We also experimented with other values for $b$ and $d_{f}$ in Eq. (1) of the short-term data but did not show significant variations in the results (Table 1 ).

We extracted 58,509 clusters from the analysis of 241,946 events for the short-term data. The clusters included 6103 families with multiple events in a cluster and 52,406 singles, which comprise one event.

An example of an extracted cluster for the 2016 M7.3 Kumamoto Earthquake sequence is shown in Fig. 3. (Another example for the 2016 M6.6 central Tottori prefecture earthquake is shown in Additional file 1: Fig. S1.) If the magnitude of the parent event (e.g., mainshock) is large, subsequent earthquakes that occur shortly after the parent event may be included in the same cluster as their parent, as child events, due to the characteristics of Eq. (1), although they occur at very large distances from the parent event (e.g., in Hokkaido for the Kumamoto mainshock). However, the events in the blue rectangle in Fig. 3a dominate the sequence over the whole period, that is, 98,682 events (97.2\% of 101,489 events). In the period from April 14 to 18 (same time span as in Fig. 3), 9868 events ( $94.3 \%$ of 10,465 events) are observed in the rectangle. Therefore, fewer distant events occurred outside the blue rectangle. Notably, 83,280 events $(82.1 \%$ of 101,489 events) are hypocenters automatically processed by the method of Tamaribuchi et al. (2016). As already shown in Fig. 1, this automatic process substantially contributes to the improvement of the JMA unified catalog.

We reconfirmed the $b$-value difference between foreshocks and aftershocks for the 2016 Kumamoto 

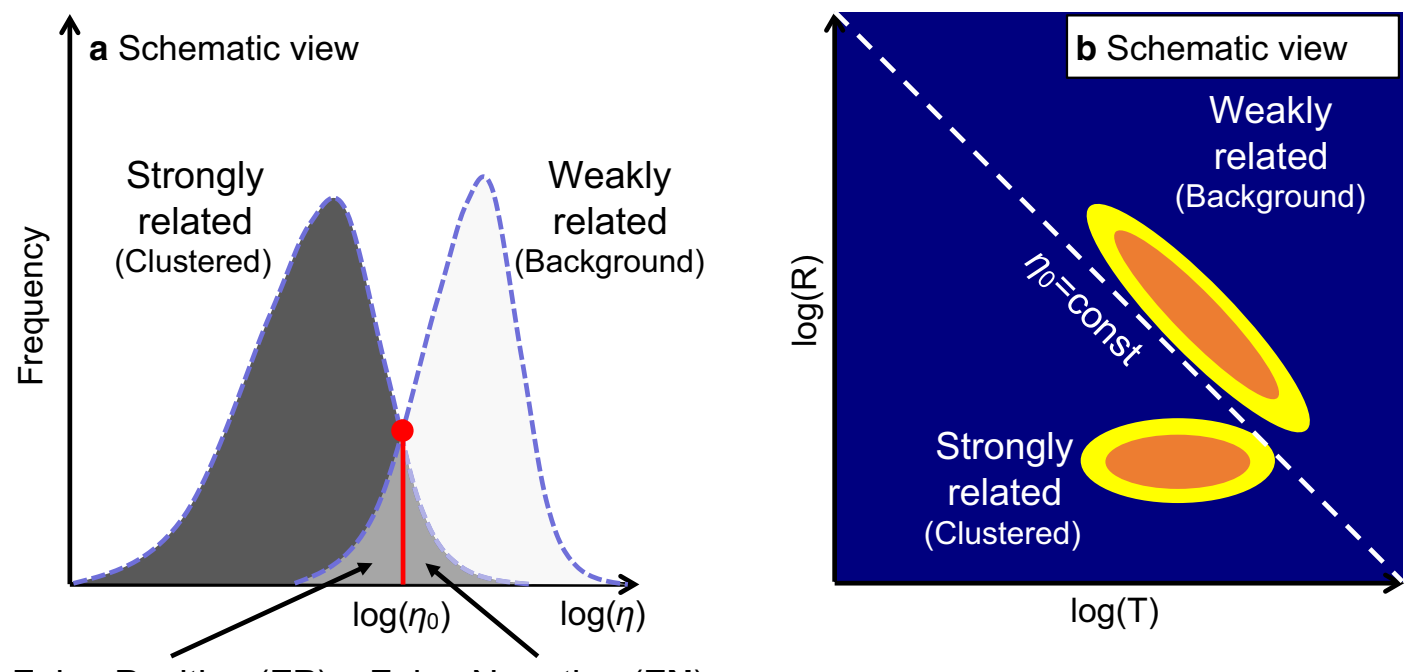

False Positive (FP) False Negative (FN)
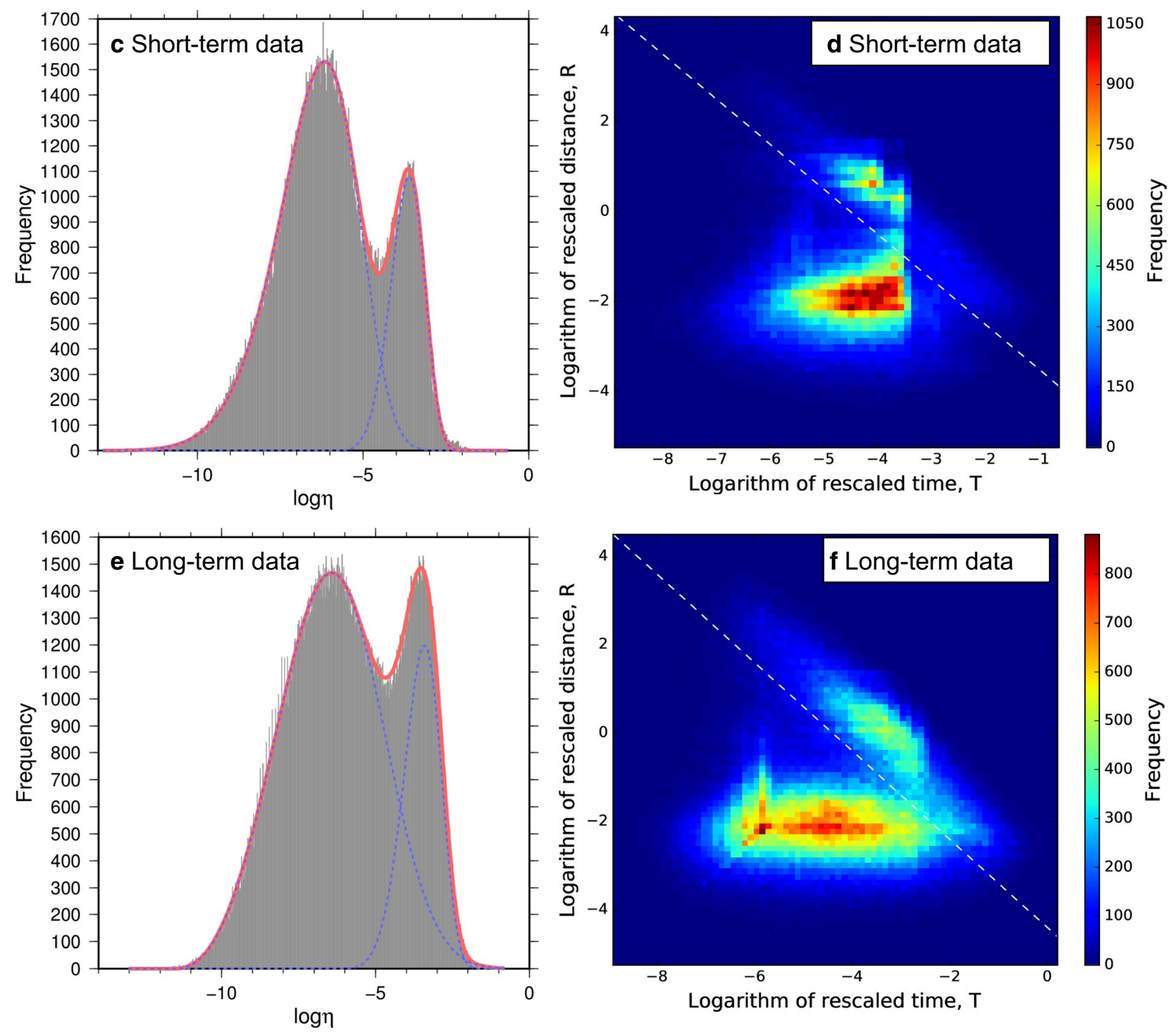
(See figure on previous page.)

Fig. 2 Distance measure using the nearest-neighbor distance analysis. $\mathbf{a}, \mathbf{b}$ Schematic view, $\mathbf{c}, \mathbf{d}$ the short-term data, and $\mathbf{e}, \mathbf{f}$ the long-term data. $\mathbf{a}, \mathbf{c}, \mathbf{e} \log \eta$ histogram. The gray area shows the frequency of $\log \eta$, the blue dotted line shows the optimal solution when assuming two Weibull distributions, and the red line shows the sum (theoretical value) of the mixed Weibull distribution. $\mathbf{b}, \mathbf{d}, \mathbf{f}$ Joint distribution with rescaled time $T$ and rescaled distance $R$. The dashed line shows $\eta_{0}$

Table 1 Parameter validity check

\begin{tabular}{lllll}
\hline $\boldsymbol{b}$ & $\boldsymbol{d}_{\boldsymbol{f}}$ & $\boldsymbol{\eta}_{\mathbf{0}}$ & FP (\%) & FN (\%) \\
\hline 1.0 & 1.6 & -4.5 & 1.9 & 3.3 \\
0.8 & 1.6 & -3.3 & 3.6 & 3.9 \\
1.2 & 1.6 & -5.7 & 2.5 & 2.4 \\
1.0 & 1.4 & -4.7 & 2.1 & 3.9 \\
1.0 & 1.8 & -4.3 & 2.6 & 2.9 \\
\hline
\end{tabular}

The input parameters, $b$ and $d_{f}$ take the values as shown above. The meaning of FP and FN is explained in Fig. $2 a$

Earthquake sequence. Since the aftershock period continues to the present, we decided to calculate the $b$-value of aftershocks using the data from the mainshock until April 2017 (Fig. 4). However, the mainshock is not included in the dataset of the foreshocks or aftershocks.
Figure 4a shows the frequency-magnitude distribution of the dataset that includes both foreshocks and aftershocks, while the foreshocks and aftershocks in Fig. 4b were separately calculated. The $b$-value is $0.62 \pm 0.02$ for foreshocks and $0.68 \pm 0.01$ for aftershocks in the case of $\mathrm{Mc}=2.0$; the $b$-value of the foreshocks is slightly lower than that of the aftershocks. We confirmed whether this $b$-value difference was significant by using the $\triangle \mathrm{AIC}$ test (Utsu 1999). The AIC (Akaike 1974) is often used as an indicator of comparison between models. One model (model 1) assumed that all earthquakes (foreshocks and aftershocks) have the same $b$-value, while the other model (model 2) assumed that foreshocks and aftershocks have their own (different) $b$-value. We calculated the AIC values of two models, and we obtained the difference of their AIC; $\triangle \mathrm{AIC}=\mathrm{AIC}($ model 1$)-\mathrm{AIC}($ model 2 ). The $b$-value difference is considered to be statistically

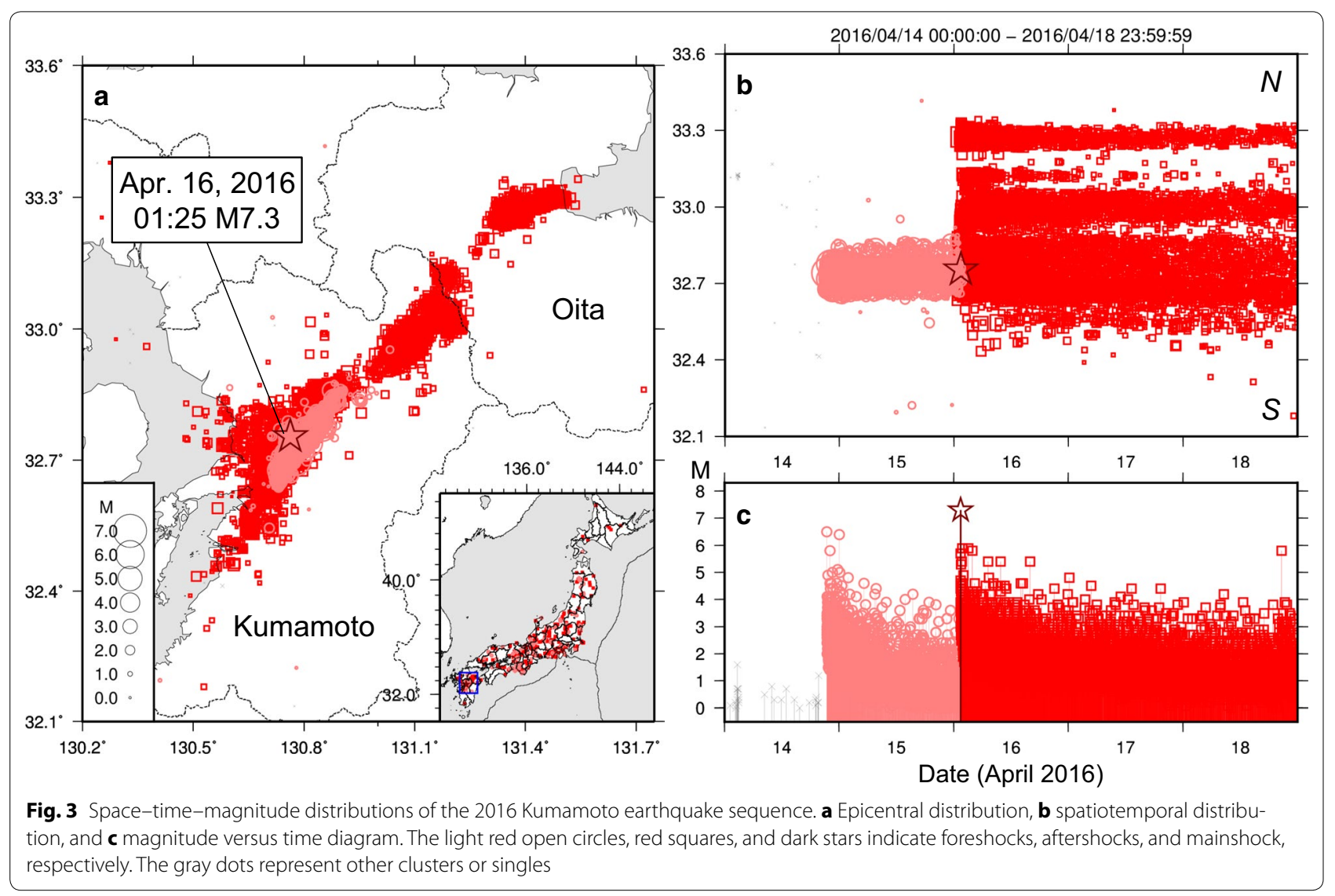



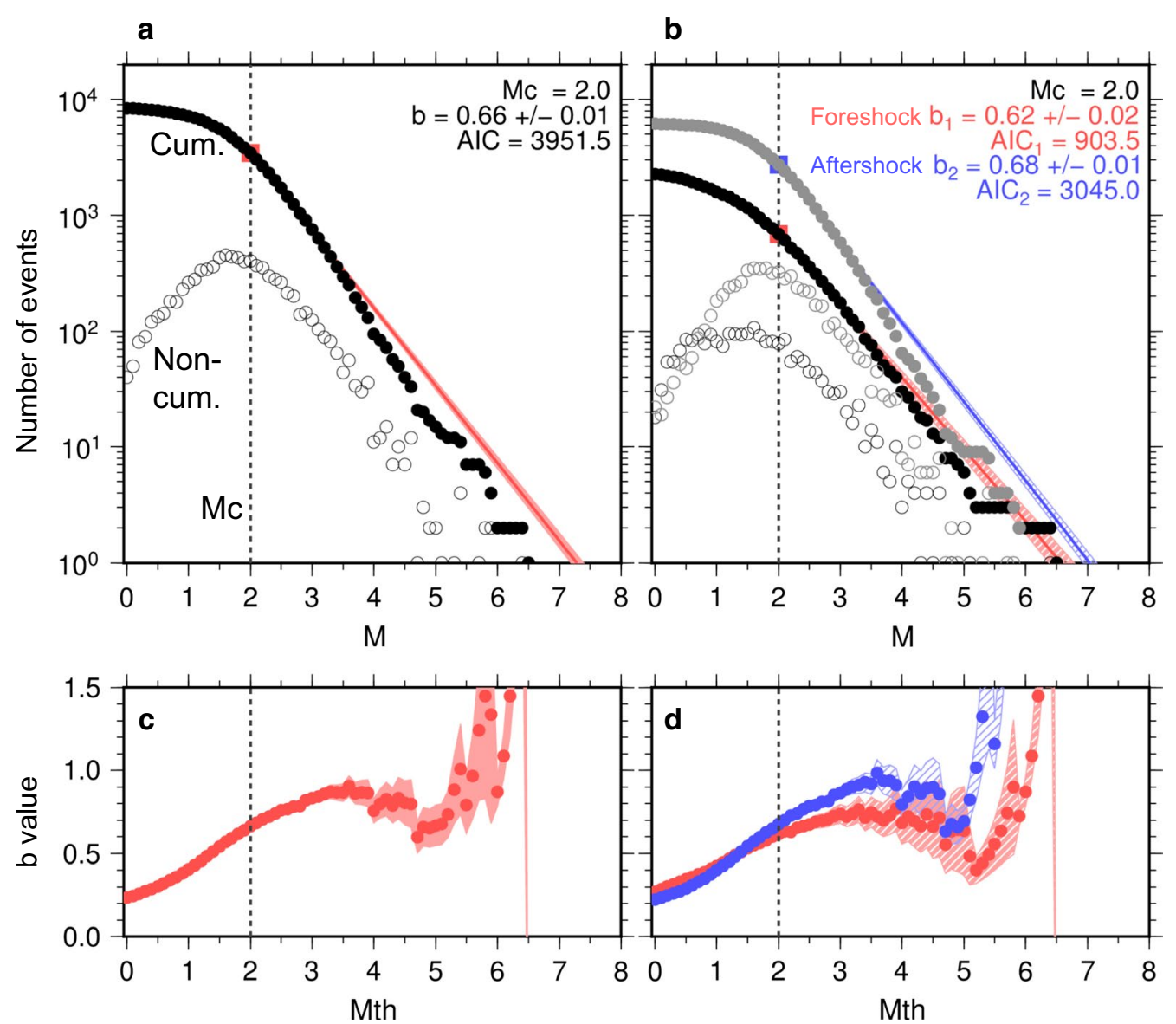

Fig. 4 Frequency-magnitude distributions of the 2016 Kumamoto earthquake sequence. a, b Frequency magnitude distributions and $\mathbf{c}$, $\mathbf{d} b$-value versus magnitude: $\mathbf{a}, \mathbf{c}$ for the entire sequence (foreshocks and aftershocks), mainshock excluded, and $\mathbf{b}$, $\mathbf{d}$ for the foreshocks and aftershocks, separately. The red and blue colors indicate foreshocks $\left(b_{1}\right)$ and aftershocks $\left(b_{2}\right)$, respectively. The frequency-magnitude distributions show both the cumulative (black) and noncumulative number (light gray) of events. The dashed black line indicates Mc estimated by the MAXC method

significant if $\triangle \mathrm{AIC}>2$. According to the $\triangle \mathrm{AIC}$ test, this difference is significant $(\triangle \mathrm{AIC}=3.0$; Fig. 4). However, the $b$-value seems to depend on the lower magnitude threshold (Mth) as shown in Fig. 4c, d. Immediately after a large earthquake, such as the Kumamoto Earthquake (M7.3), many small events are usually missing; thus, $\mathrm{Mc}=2.0$, estimated by MAXC method, might underestimate the completeness magnitude shortly after the mainshock. Therefore, we also confirmed the $b$-value for the cases of Mc $=3.0$ or 4.0. Even in these cases, the $b$-value of the foreshocks is lower, that is, $0.74 \pm 0.06$ for foreshocks compared with $0.86 \pm 0.03$ for aftershocks $(M \geq 3.0)$ and the $b$-value of $0.68 \pm 0.13$ for foreshocks compared with $0.79 \pm 0.09$ for the aftershocks $(M \geq 4.0)$. However, we cannot conclude that there is a statistically significant difference according to the $\triangle \mathrm{AIC}$ test $(\triangle \mathrm{AIC}=1.6$ for $M \geq 3.0$, and $\triangle \mathrm{AIC}=-1.6$ for $M \geq 4.0$ ). To confirm the obtained $b$-values, we also used the method of Omi et al. (2013), which takes the temporal change of Mc into consideration. They adopted the time-dependent function of the detection rate and estimated the $b$-value more robustly. We used the data starting 1 day after the April 14 M6.5 earthquake for the foreshocks and that from the April 16 M7.3 earthquake (mainshock) for the aftershocks. In this case, the mainshock is included in the aftershock dataset. The resulting $b$-value is $0.65 \pm 0.19$ for the foreshocks and $0.98 \pm 0.22$ for the aftershocks; thus, the $b$-value of the foreshocks is lower than that of the aftershocks as reported by Nanjo and Yoshida (2017) and ERC (2016). We also mention that the same $b$-value is obtained even if the mainshock is excluded from the aftershock dataset.

To extract detailed seismicity characteristics for the whole catalog, we classified all earthquakes of the longterm data as families (mainshocks, foreshocks, and aftershocks) and singles. Table 2 summarizes the classification results. Among all the detected earthquakes, $12 \%$ were foreshocks and $62 \%$ were aftershocks. There are four 
Table 2 Statistics of singles, mainshocks, aftershocks, and foreshocks using the nearest-neighbor distance analysis of long-term data

\begin{tabular}{|c|c|c|c|c|c|c|c|c|c|}
\hline \multirow{3}{*}{$\begin{array}{l}\text { Magnitude range } \\
\text { All events: } M \geq 0\end{array}$} & \multirow{3}{*}{$\begin{array}{l}\text { Singles } \\
93,938\end{array}$} & \multirow[b]{3}{*}{$22 \%$} & \multicolumn{6}{|c|}{ Families } & \multirow{3}{*}{$\begin{array}{l}\text { All } \\
429,626\end{array}$} \\
\hline & & & \multicolumn{2}{|c|}{ Mainshocks } & \multicolumn{2}{|c|}{ Aftershocks } & \multicolumn{2}{|c|}{ Foreshocks } & \\
\hline & & & 17,700 & $4 \%$ & 265,656 & $62 \%$ & 52,332 & $12 \%$ & \\
\hline $1 \leq M<2$ & 87,014 & $24 \%$ & 9990 & $3 \%$ & 219,297 & $61 \%$ & 41,847 & $12 \%$ & 358,148 \\
\hline $2 \leq M<3$ & 6676 & $11 \%$ & 5934 & $10 \%$ & 39,884 & $65 \%$ & 8960 & $15 \%$ & 61,454 \\
\hline $3 \leq M<4$ & 245 & $3 \%$ & 1480 & $17 \%$ & 5674 & $65 \%$ & 1315 & $15 \%$ & 8714 \\
\hline $4 \leq M<5$ & 3 & $0 \%$ & 248 & $22 \%$ & 718 & $62 \%$ & 184 & $16 \%$ & 1153 \\
\hline $5 \leq M<6$ & 0 & $0 \%$ & 35 & $27 \%$ & 76 & $58 \%$ & 20 & $15 \%$ & 131 \\
\hline $6 \leq M<7$ & 0 & $0 \%$ & 9 & $41 \%$ & 7 & $32 \%$ & 6 & $27 \%$ & 22 \\
\hline $7 \leq M$ & 0 & $0 \%$ & 4 & $100 \%$ & 0 & $0 \%$ & 0 & $0 \%$ & 4 \\
\hline
\end{tabular}

sequences with a M7 mainshock: (A) the M7.3 Western Tottori Earthquake on October 6, 2000; (B) M7.2 Iwate-Miyagi Nairiku Earthquake on June 14, 2008; (C) M7.0 Eastern Fukushima Earthquake on April 11, 2011; and (D) M7.3 Kumamoto Earthquake on April 16, 2016 (Fig. 1). The M7.3 Western Tottori Earthquake did not show a foreshock activity, while the M7.2 Iwate-Miyagi Nairiku Earthquake had a M1.3 foreshock at 8:11, only 30 min before the mainshock. In the case of the M7.0 Eastern Fukushima Earthquake, the foreshock activity started with the M5.7 quake on March 11, shortly after the 2011 Tohoku-oki Earthquake. As already mentioned, two large foreshocks of $M>6.0$ were recorded in the case of the 2016 Kumamoto Earthquake sequence, that is, the April 14 M6.5 and April 15 M6.4 earthquakes.

We further extracted both foreshocks and aftershocks of families with 200 or more events and investigated the $b$-value difference between the foreshocks and aftershocks. Aftershocks usually span over a considerably longer period compared to the foreshock activity. To focus on the $b$-value characteristics close to the time of the mainshock occurrence, we chose a time window of 200 events (for which we determined Mc and $b$ ). Because $b$-values likely depend on the tectonic region in which the seismic activity takes place, we compared the $b$-values of the foreshocks and aftershocks with the $b$-value of the background seismicity. The $b$-value of the background seismicity was calculated using hypocenters other than the target cluster within a range of $\pm 0.4^{\circ}$ from the mainshock's epicenter of the target cluster. The comparison of the $b$-value differences for different magnitudes of the mainshock is shown in Fig. 5a and Table 3a. Most $b$-value differences are insignificant according to the $\triangle \mathrm{AIC}$ test; however, the overall tendency does not depend on the mainshock magnitude $\left(M_{\text {main }}\right)$, and the $b$-value of the foreshocks tends to be relatively low. When the mainshock magnitude increases, the $b$-values of both aftershocks and foreshocks tend to be lower than the background $b$-value. In case of the large mainshocks $\left(M_{\text {main }} \geq 5.5\right)$, the lack of catalog data immediately after the mainshock may lead to $b$-value underestimation. Therefore, we also estimated the $b$-value by fixing $\mathrm{Mc}=M_{\text {main }}-3.5$ for $M_{\text {main }} \geq 5.5$. Under this condition, the tendency toward a low $b$-value of the foreshocks does not change, although the number of events $(\geq M c)$ decreases (Fig. 5b and Table 3b). However, when calculating the $b$-value of aftershocks ( $\geq 200$ events) for sequences without foreshocks or with a small number of foreshocks ( $<200$ events), the variation is quite large (Fig. 5c-f), and thus, it would be difficult to judge from the $b$-values alone, in quasi-real time, if it is a foreshock or an aftershock sequence. The anomalously high $b$-value $(\Delta b>1.0$, Group ID \#6 in Table 3a) is associated with swarm-like activities around the Mt. Sharitake volcano in the eastern part of Hokkaido. Notably, this $b$-value is out of range in Fig. 5a, b.

Earthquake forecasting applications would benefit from examining how often the mainshock would occur (and its magnitude, timing, and location) when assuming that ongoing clustered seismicity is a foreshock activity. Therefore, the percentage of families with a foreshock activity was determined to verify how many mainshocks were accompanied by foreshocks. Figure 6a shows that the percentage of families (without singles) with a foreshock activity is approximately $30-40 \%$ in the range of M1-5 for the mainshocks and approximately $70 \%$ in the range of M5-7. When focusing on at least 100 samples, the percentage (rate) of foreshock occurrence appears to be independent of the mainshock magnitude (M1-5). The number of singles increases for smaller magnitudes. Therefore, if singles are included in the calculations, the percentage of foreshock occurrence approaches zero in the small magnitude range (see Fig. 6a, dashed red line). We also observed that the frequency distribution of the 

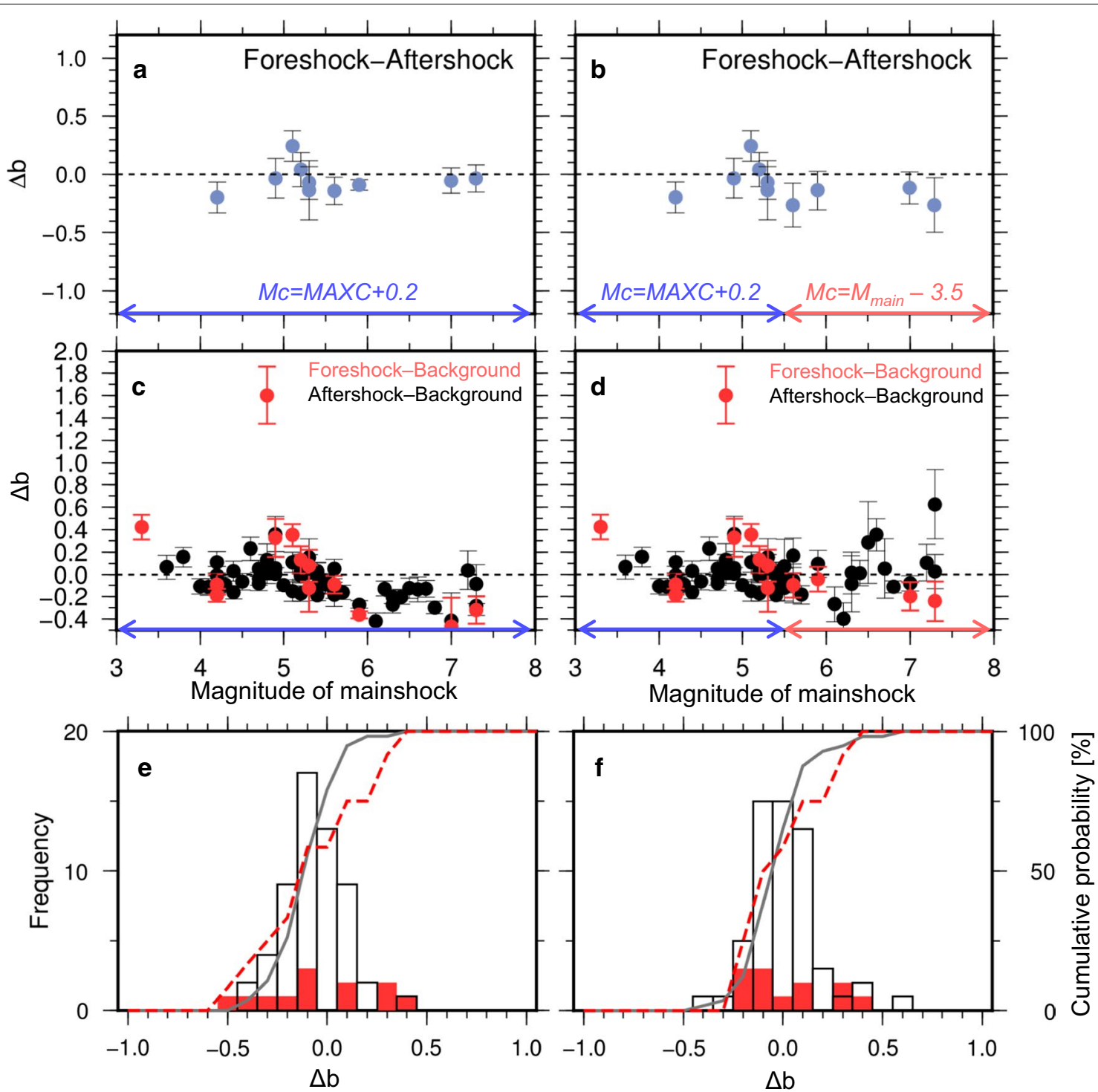

Fig. 5 Comparison of $b$-value differences. a-d Comparison of the magnitude of the mainshock and $b$-value differences. The magnitude of the mainshock is shown on the horizontal axis; the vertical axis shows the $b$-value difference. a, b Foreshocks-aftershocks (with 200 foreshocks and 200 aftershocks), c, d foreshocks-background (with 200 foreshocks, red circle), and aftershocks-background (with 200 aftershocks, black circle). e, f Histogram of $b$-value differences. The frequency of the $b$-value differences is on the left axis, and the cumulative probability is shown on the right axis. $\mathbf{a}, \mathbf{c}$, e Mc was chosen as MAXC +0.2 for the entire magnitude range, $\mathbf{b}, \mathbf{d}, \mathbf{f} \mathbf{~ M c}$ was chosen as MAXC +0.2 for $M_{\text {main }}<5.5 ; M_{\text {main }}-3.5$ for $M_{\text {main }} \geq 5.5$. The $b$-value of the background was calculated using hypocenters other than the target cluster within the range of \pm 0.4 degree of the mainshock of the target cluster

magnitude difference between the mainshock and largest foreshock (Fig. 6b) follows a power law; that is, the mainshock magnitude tends to be close to the magnitude of the largest foreshock. The frequency of $\Delta M$ decreases by $1 / 10$ per unit.

Figure 7 shows the time difference and epicentral distance of the largest foreshock relative to its mainshock, respectively. Approximately $50 \%$ of the mainshocks occurred within a day after the largest foreshock
$(M \geq 1.0$, Fig. 7a), and the time difference between the largest foreshock and mainshock $(\Delta t)$ attenuates as $1 / \Delta t$ between 0.1 and 10 days (Fig. 7c). However, approximately 1 week is required for the mainshock to occur in $50 \%$ of the cases of $M \geq 2.5$ foreshocks. The larger the magnitude of the foreshock, the longer is the time difference between the largest foreshock and mainshock. Because, generally, larger mainshocks have larger foreshocks (see above), a strong link between them at longer 
Table 3 Statistics of clusters with 200 or more foreshocks and aftershocks

\begin{tabular}{|c|c|c|c|c|c|c|c|c|c|c|c|c|c|c|}
\hline \multirow{2}{*}{$\begin{array}{l}\text { Group } \\
\text { ID }\end{array}$} & \multicolumn{3}{|c|}{ Mainshock } & \multirow[t]{2}{*}{ Mc } & \multicolumn{3}{|c|}{ Foreshock } & \multicolumn{3}{|c|}{ Aftershock } & \multicolumn{3}{|c|}{ Background } & \multirow[t]{2}{*}{$\Delta \mathrm{AIC}$} \\
\hline & Lat $\left(^{\circ}\right)$ & Lon $\left({ }^{\circ}\right)$ & $M$ & & $N(\geq M c)$ & $b$ & $\sigma_{b}$ & $N(\geq M c)$ & $b$ & $\sigma_{b}$ & $N(\geq M c)$ & $b$ & $\sigma_{b}$ & \\
\hline \multicolumn{15}{|c|}{ (a) $M C=M A X C+0.2$ for the entire magnitude range } \\
\hline 1 & 31.84 & 130.29 & 4.2 & 1.2 & 131 & 0.95 & 0.09 & 140 & 1.15 & 0.10 & 4171 & 1.04 & 0.02 & 0.5 \\
\hline 2 & 34.96 & 139.18 & 5.9 & 1.3 & 153 & 0.50 & 0.03 & 155 & 0.59 & 0.03 & 3234 & 0.86 & 0.01 & 0.3 \\
\hline 3 & 36.33 & 137.63 & 5.6 & 1.7 & 92 & 0.75 & 0.08 & 87 & 0.90 & 0.09 & 2826 & 0.85 & 0.02 & -0.6 \\
\hline 4 & 35.28 & 135.93 & 5.2 & 1.3 & 110 & 1.02 & 0.12 & 105 & 0.98 & 0.09 & 4055 & 0.89 & 0.01 & -1.9 \\
\hline 5 & 42.50 & 140.83 & 4.9 & 1.8 & 65 & 1.12 & 0.13 & 71 & 1.16 & 0.11 & 37 & 0.80 & 0.11 & -2.0 \\
\hline 6 & 43.74 & 144.70 & 4.8 & 1.6 & 42 & 2.53 & 0.25 & 56 & 1.06 & 0.13 & 360 & 0.93 & 0.06 & 14.9 \\
\hline 7 & 37.30 & 136.84 & 5.3 & 2.7 & 71 & 0.75 & 0.08 & 23 & 0.83 & 0.12 & 19 & 0.68 & 0.12 & -1.9 \\
\hline 8 & 34.96 & 139.13 & 5.1 & 1.4 & 78 & 1.11 & 0.10 & 89 & 0.87 & 0.09 & 5362 & 0.76 & 0.01 & 0.5 \\
\hline 9 & 36.95 & 140.67 & 7.0 & 3.2 & 30 & 0.57 & 0.10 & 114 & 0.63 & 0.05 & 9 & 1.04 & 0.24 & -1.8 \\
\hline 10 & 32.75 & 130.76 & 7.3 & 3.1 & 50 & 0.69 & 0.10 & 126 & 0.72 & 0.06 & 166 & 1.00 & 0.07 & -1.9 \\
\hline 11 & 31.38 & 130.62 & 5.3 & 1.8 & 27 & 1.02 & 0.20 & 34 & 1.16 & 0.15 & 275 & 1.15 & 0.06 & -1.8 \\
\hline \multicolumn{15}{|c|}{ (b) $M c=M_{\text {main }}-3.5$ for $M_{\text {main }} \geq 5.5$} \\
\hline 2 & 34.96 & 139.18 & 5.9 & 2.4 & 47 & 0.82 & 0.11 & 31 & 0.96 & 0.12 & 3234 & 0.86 & 0.01 & -1.5 \\
\hline 3 & 36.33 & 137.63 & 5.6 & 2.1 & 45 & 0.74 & 0.11 & 40 & 1.00 & 0.15 & 2826 & 0.85 & 0.02 & 0. \\
\hline 9 & 36.95 & 140.67 & 7.0 & 3.5 & 21 & 0.59 & 0.12 & 81 & 0.71 & 0.06 & 9 & 1.04 & 0.24 & -1.4 \\
\hline 10 & 32.75 & 130.76 & 7.3 & 3.8 & 15 & 0.62 & 0.18 & 42 & 0.89 & 0.15 & 166 & 1.00 & 0.07 & -0.5 \\
\hline
\end{tabular}

Lat., Lon., and $M$ indicate the latitude, longitude, and magnitude of the mainshock, respectively. Mc indicates the completeness magnitude. The parameters, $b$ and $\sigma_{b}$, are the $b$-value and its uncertainty, respectively. $\triangle \mathrm{AIC}$ indicates the difference of AIC values (Utsu 1999). a Mc was chosen as MAXC +0.2 for the entire magnitude range, $\mathrm{b}$ Mc was chosen as $M_{\text {main }}-3.5$ for $M_{\text {main }} \geq 5.5$
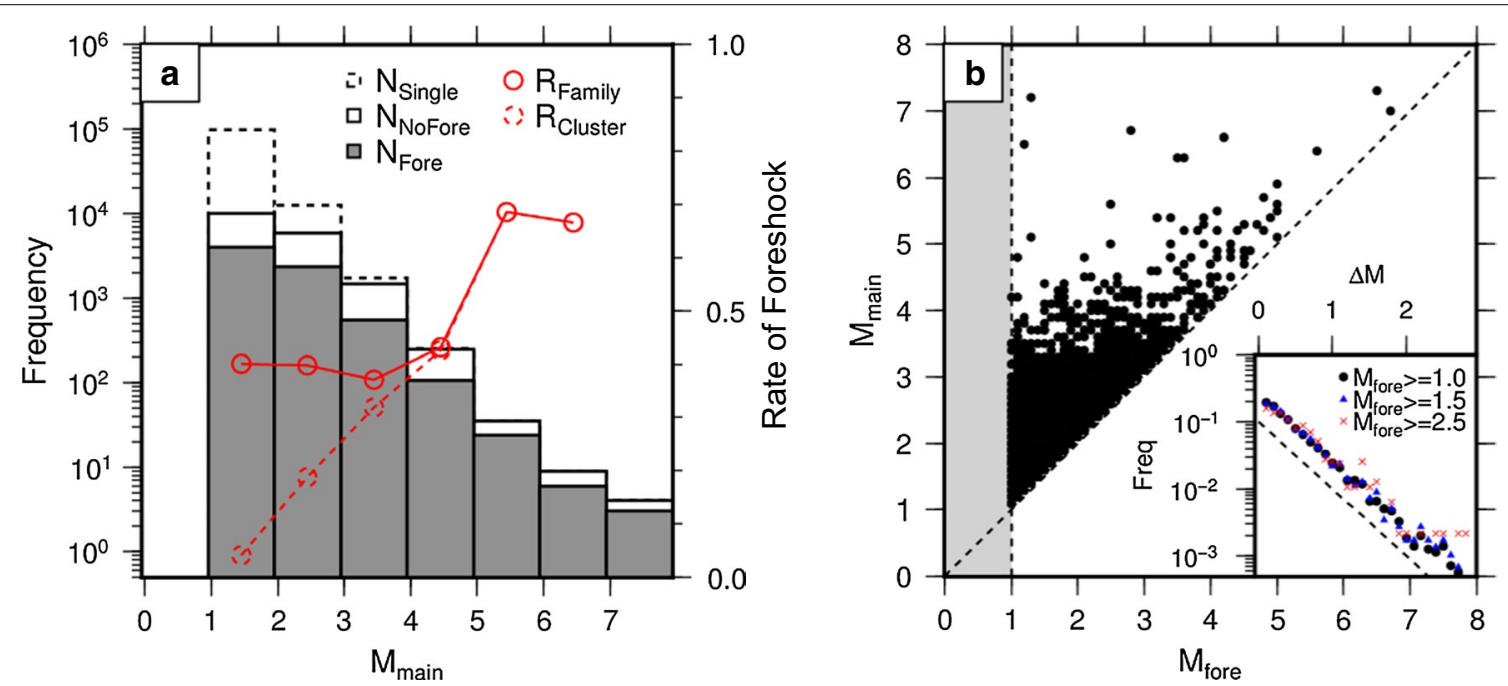

Fig. 6 Frequency-magnitude distribution and relationship between the largest foreshock and its mainshock for the long-term data. a Frequencymagnitude distribution and percentage of foreshock occurrence. The white solid and dashed histograms show the frequency of mainshocks versus their magnitude for all families (without singles) and clusters (with singles), respectively; the gray histogram shows the frequency of mainshocks that are accompanied by foreshocks (left axis). The red solid and dashed lines show the proportion of sequences that have foreshocks for all families and clusters, respectively (right axis). b Relationship between the magnitude of the largest foreshock and the corresponding mainshock magnitude for each earthquake cluster. The gray shading indicates $M \leq 1.0$ (potentially incomplete data). The lower right inset shows the frequency distribution of the magnitude difference between the mainshock and largest foreshock. The dashed line has a slope of 1.0. The black dots, blue triangles, and red crosses indicate that the magnitude of the largest foreshock is above 1.0, 1.5, and 2.5, respectively 


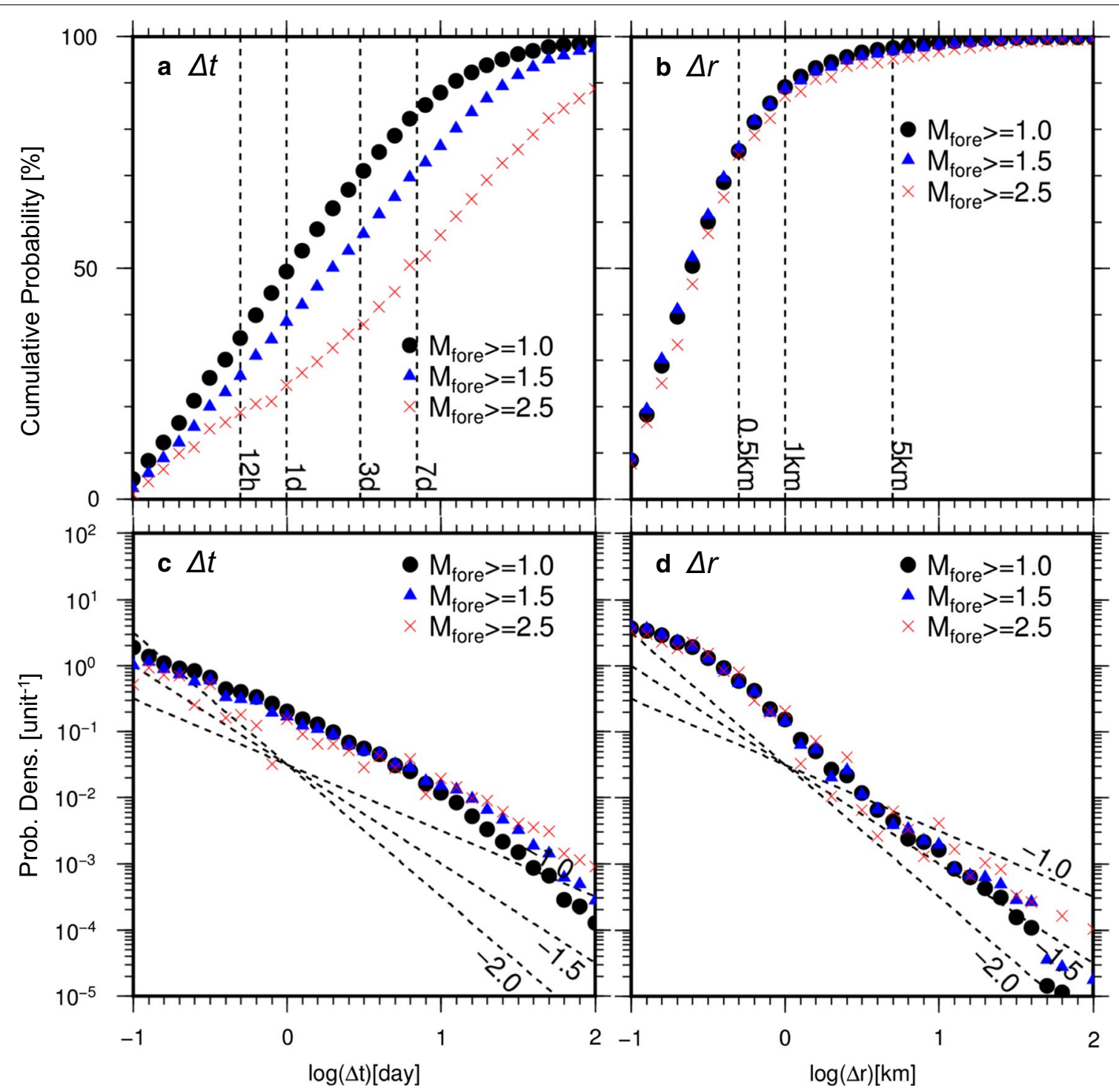

Fig. 7 Cumulative probability and frequency density distribution of the time difference $(\Delta t)$ and the epicentral distance $(\Delta r)$ between the largest foreshock and mainshock for long-term data. a, cTime difference $(\Delta t)$ and $\mathbf{b}$, d epicentral distance $(\Delta r)$. $\mathbf{a}, \mathbf{b}$ Cumulative probability distribution. $\mathbf{b}$. d Probability density distribution. The dashed lines have slopes of $-1.0,-1.5$, and -2.0 , as indicated in the figure. The black dots, blue triangles, and red crosses indicate that the magnitude of the largest foreshock is above 1.0, 1.5, and 2.5, respectively

time differences is more commonly observed. The distribution of the distance between the largest foreshock and mainshock $(\Delta r)$ is shown in Fig. 7b. Approximately $90 \%$ of the mainshocks occur within a range of $1 \mathrm{~km}$ from their largest foreshock. The frequency of $\Delta r$ attenuates as $1 / \Delta r^{2}$ (Fig. $7 \mathrm{~d}$ ). The distribution does not strongly depend on the magnitude of the foreshock, in contrast to the time difference. Whether purely statistical in nature or reflecting some physical generation mechanisms, the time difference and epicentral distance characteristics may be useful for better hazard assessment of large earthquakes (Fig. 7).

\section{Discussion}

The $b$-value difference between foreshocks and aftershocks has been discussed in many studies. Recently, several studies pointed out that the $b$-value of foreshocks decreases before major subduction-zone earthquakes, such as the 2011 Tohoku-oki and 2014 Iquique earthquakes, due to the stress accumulation before the megathrust events (e.g., Nanjo et al. 2012; Tormann et al. 2015; Schurr et al. 2014). The $b$-value after the 2011 Tohoku-oki Earthquake increased relatively rapidly, which may reflect the heterogeneous stress recovery process after the megathrust event (Tormann et al. 2015, 
2016). As Tormann et al. (2016) suggested, the $b$-values possibly react less to the absolute stress levels and more to the homogeneity of the stress field, which would have been disturbed during the mainshock rupture and could likely recover more easily via aftershocks. Figure 5 shows not only a $b$-value difference between foreshocks and aftershocks for the large Kumamoto Earthquake (Fig. 4) but also over a wide magnitude range of $\mathrm{M} 3-7$ for the entire analyzed catalog. If the $b$-value is related to differential stress, as discussed in laboratory and actual seismicity studies (Scholz 1968; Amitrano 2003; Schorlemmer et al. 2005; Scholz 2015), this would indicate the stress accumulation before mainshocks. However, from the point of view of classifying foreshocks and aftershocks based on their $b$-values, our results suggest that it is quite difficult to distinguish them. Further investigations are necessary to describe them probabilistically in more detail.

If the "stress level" reflects the closeness to a critical threshold of differential stress (Scholz 1968), the $b$-value change during foreshocks and aftershocks is likely due to the spatial heterogeneity of the stress distribution. Generally, when the increase in the stress at long wavelengths is dominant, the rupture tends to expand (i.e., larger earthquakes tend to occur more frequently), which results in lower $b$-values. Conversely, when the increase in the stress at short wavelengths is dominant, the rupture does not spread smoothly, which results in higher $b$-values (Scholz 1968). A decrease in the $b$-values before the mainshocks corresponds to the predominance of long wavelengths, relatively large stress levels, and is caused by the stress accumulation process before the earthquake. Short-wavelength (i.e., highly heterogeneous) stresses become dominant after the mainshock, and the $b$-value increases due to the stress release for the "wavelength" that corresponds to the mainshock magnitude. Considering that the increase in stress at long wavelengths (e.g., those caused by the Earth tides; Ide et al. 2016) leads to a decrease in the $b$-value and relatively high probability of the occurrence of a large earthquake, stress changes should be observed at various wavelengths to understand the preparation process of huge earthquakes.

Figure 6a shows that the percentage of clusters (without singles) with a foreshock activity is approximately $30-40 \%$ in the range of M1-4 for the mainshocks. This percentage (rate) of foreshock occurrence appears to be independent of the mainshock magnitude. Abercrombie and Mori (1996) showed that the rate of foreshock occurrence in California is approximately $40 \%$ in the range of M5-6 for the mainshocks, without magnitude dependence. The result of this study suggests that the rate of foreshock occurrence might be relatively constant (30$40 \%$ ) for a wider magnitude range.
The frequency distribution of the magnitude difference between the mainshock and largest foreshock follows a power law (Fig. 6b). Investigation of the physical nature of this power law in detail is beyond the scope of this study; however, our results suggest that the size of the mainshock could be estimated from the foreshock activity in a probabilistic way (Jones 1985). As shown in Fig. 7, the time difference and epicentral distance between the mainshock and largest foreshock can also contribute to the estimation of the probability of mainshock occurrence.

By further extending the completeness and homogeneity of earthquake catalogs, probabilistic forecasting of earthquakes is expected to improve based on better statistics and a wider, more complete magnitude range. The progress in the development of automatic processing techniques (e.g., Yoon et al. 2015; Tamaribuchi et al. 2016 for hypocenter determination and Omi et al. 2013 for $b$-value estimation) will become increasingly important.

\section{Conclusion}

We analyzed the long-term and wide magnitude range of foreshock activity using the JMA unified catalog from 1997 to 2017. By objectively clustering the inland, shallow seismicity, we identified foreshocks and aftershocks and analyzed their statistical characteristics. Our systematic investigation supports the previous findings, mainly based on the analysis of individual sequences, that the $b$-value of foreshocks is slightly lower than that of the aftershocks over a wide magnitude range of M3-7 (although the differences are rather subtle and, probably, still difficult to use for prospective earthquake forecasting). This result suggests that factors, such as the stress interactions induced either seismically or aseismically, may also contribute to the mainshock-triggering/nucleation process. We also analyzed the characteristics of the magnitude and occurrence time differences, as well as epicentral distance between the mainshock and the largest foreshock and confirmed that they follow a power law. We expect that the characteristics of seismic activity will become clearer with further enhancement of the number of cataloged earthquakes due to progress in the processing for automatic hypocenter determination.

\section{Additional file}

Additional file 1: Fig. S1. Space-time-magnitude distributions of the Central Tottori earthquake (from October 21, 2016, to October 23, 2016). a Epicentral distribution, $\mathbf{b}$ spatiotemporal distribution, and $\mathbf{c}$ magnitude versus time diagram. The light red open circles, red squares, and dark stars indicate foreshocks, aftershocks, and mainshock, respectively. The gray dots represent other clusters or singles. 


\section{Abbreviations}

AIC: Akaike information criteria; ETAS: epidemic type aftershock sequence; JMA: Japan Meteorological Agency; ERC: Earthquake Research Committee; MEXT: Ministry of Education, Culture, Sports, Science and Technology; NIED: National Research Institute for Earth Science and Disaster Resilience; G-R law: Gutenberg-Richter law.

\section{Authors' contributions}

KT performed the analysis and drafted the manuscript. YY participated in the design of the study. BE and $\mathrm{SH}$ contributed to interpretation of results and a part of the discussion. All the authors participated in discussions and contributed to revising an earlier draft of the manuscript. All authors read and approved the final manuscript.

\section{Author details}

${ }^{1}$ Meteorological Research Institute, Japan Meteorological Agency, Tsukuba, Japan. ${ }^{2}$ Faculty of Life and Environmental Sciences, University of Tsukuba, Tsukuba, Japan. ${ }^{3}$ Department of Geophysics, Graduate School of Science, Kyoto University, Kyoto, Japan. ${ }^{4}$ Department of Physical Science, College of Science and Engineering, Ritsumeikan University, Kusatsu, Japan.

\section{Acknowledgements}

We thank the Editor Takuto Maeda and two anonymous reviewers for their helpful comments. The earthquake catalog is produced by the JMA in cooperation with MEXT. We used a python package (AftFore: https://githu b.com/omitakahiro/AftFore) coded by T. Omi to estimate the $b$-value. We used generic mapping tools (GMT; Wessel et al. 2013) to draw the figures. Authors acknowledge the partial support from the Japan Society for the Promotion of Science (JSPS) KAKENHI Grant 16K05529 and 16H06477 (to Y. Yagi).

\section{Competing interests}

The authors declare that they have no competing interests.

\section{Availability of data and materials}

The data used in this article are available at the Data Management Center of NIED (http://www.hinet.bosai.go.jp/?LANG=en) and JMA (http://www.data. jma.go.jp/svd/eqev/data/bulletin/index_e.html).

\section{Consent for publication}

Not applicable.

\section{Ethics approval and consent to participate}

Not applicable.

\section{Funding}

Authors acknowledge the partial support from the Japan Society for the Promotion of Science (JSPS) KAKENHI Grant 16 K05529 and $16 \mathrm{H06477}$ (to Y. Yagi).

\section{Publisher's Note}

Springer Nature remains neutral with regard to jurisdictional claims in published maps and institutional affiliations.

Received: 14 January 2018 Accepted: 18 May 2018

Published online: 29 May 2018

\section{References}

Abercrombie RE, Mori J (1996) Characteristics of foreshock occurrence to large earthquakes in the western United States. Nature 381(6580):303-307

Akaike H (1974) A new look at the statistical model identification. IEEE Trans Automat Contr 19(6):716-723. https://doi.org/10.1109/TAC.1974.1100705

Aki K (1965) Maximum likelihood estimate of $b$ in the formula $\log (N)=a-b M$ and its confidence limits. Bull Earthq Res Inst Tokyo Univ 43:237-239

Amitrano D (2003) Brittle-ductile transition and associated seismicity: experimental and numerical studies and relationship with the b value. $J$ Geophys Res 108(B1):2044. https://doi.org/10.1029/2001JB000680

Baiesi M, Paczuski M (2004) Scale-free networks of earthquakes and aftershocks. Phys Rev E 69(6):066106
Earthquake Research Committee (1998) Aftershock probability evaluation methods. http://www.jishin.go.jp/main/yoshin2-e/yoshin2.htm. Accessed 15 Sep 2017

Earthquake Research Committee (2016) Guidelines for the seismic forecast information after big earthquakes. http://www.jishin.go.jp/reports/resea rch_report/yosoku_info/. Accessed 15 Sep 2017

Enescu B, Ito K (2001) Some premonitory phenomena of the 1995 HyogoKen Nanbu (Kobe) earthquake: seismicity, b-value and fractal dimension. Tectonophysics 338(3-4):297-314. https://doi.org/10.1016/S0040 $-1951(01) 00085-3$

Frohlich C, Davis SD (1990) Single-link cluster analysis as a method to evaluate spatial and temporal properties of earthquake catalogues. Geophys J Int 100(1):19-32. https://doi.org/10.1111/j.1365-246X.1990.tb04564.x

Helmstetter A, Sornette D, Grasso JR (2003) Mainshocks are aftershocks of conditional foreshocks: how do foreshock statistical properties emerge from aftershock laws. J Geophys Res 108:2046. https://doi.org/10.1029/2002J B001991

Ide S, Yabe S, Tanaka Y (2016) Earthquake potential revealed by tidal influence on earthquake size-frequency statistics. Nat Geosci 9:834-839. https:// doi.org/10.1038/ngeo2796

Japan Meteorological Agency (2017) The seismological bulletin of Japan. http://www.data.jma.go.jp/svd/egev/data/bulletin/catalog/notes_e.html. Accessed 1 Mar 2017

Jones LM (1985) Foreshocks and time-dependent earthquake hazard assessment in Southern California. Bull Seismol Soc Am 75(6):1669-1679

Kasahara A (2016) An implementation of Zaliapin and Ben-Zion (2013, JGR). https://github.com/kshramt/trial_kshramt. Accessed 6 Jan 2017

Kato A, Obara K, Igarashi T, Tsuruoka H, Nakagawa S, Hirata N (2012) Propagation of slow slip leading up to the 2011 Mw 9.0 Tohoku-Oki Earthquake. Science 335:705-708. https://doi.org/10.1126/science.1215141

Kato A, Fukuda JI, Nakagawa S, Obara K (2016) Foreshock migration preceding the 2016 Mw 7.0 Kumamoto earthquake, Japan. Geophys Res Lett 43(17):8945-8953. https://doi.org/10.1002/2016GL070079

Maeda K (1996) The use of foreshocks in probabilistic prediction along the Japan and Kuril trenches. Bull Seismol Soc Am 86(1A):242-254

Marsan D, Enescu B (2012) Modeling the foreshock sequence prior to the 2011, Mw9.0 Tohoku, Japan, earthquake. J Geophys Res 117(B6):B06316. https://doi.org/10.1029/2011JB009039

Marsan D, Helmstetter A, Bouchon M, Dublanchet P (2014) Foreshock activity related to enhanced aftershock production. Geophys Res Lett 41(19):6652-6658. https://doi.org/10.1002/2014GL061219

Nanjo KZ, Yoshida A (2017) Anomalous decrease in relatively large shocks and increase in the $p$ and $b$ values preceding the April 16, 2016, M7.3 earthquake in Kumamoto, Japan. Earth Planets Space 69:13. https://doi. org/10.1186/s40623-017-0598-2

Nanjo KZ, Ishibe T, Tsuruoka H, Schorlemmer D, Ishigaki Y, Hirata N (2010) Analysis of the completeness magnitude and seismic network coverage of Japan. Bull Seismol Soc Am 100(6):3261-3268. https://doi. org/10.1785/0120100077

Nanjo KZ, Hirata N, Obara K, Kasahara K (2012) Decade-scale decrease in b value prior to the M9-class 2011 Tohoku and 2004 Sumatra quakes. Geophys Res Lett 39(20):L20304. https://doi.org/10.1029/2012GL052997

Ogata Y (1988) Statistical models for earthquake occurrences and residual analysis for point processes. J Am Stat Assoc 83(401):9-27

Ogata Y, Katsura K (2012) Prospective foreshock forecast experiment during the last 17 years. Geophys J Int 191:1237-1244. https://doi.org/10.1111/ j.1365-246X.2012.05645.X

Ogata Y, Katsura K (2014) Comparing foreshock characteristics and foreshock forecasting in observed and simulated earthquake catalogs. J Geophys Res Solid Earth 119(11):8457-8477. https://doi.org/10.1002/2014JB0112 50

Okada Y, Kasahara K, Hori S, Obara K, Sekiguchi S, Fujiwara H, Yamamoto A (2004) Recent progress of seismic observation networks in Japan -Hi-net, F-net, K-NET and KiK-net-. Earth Planets Space 56:xv-xxviii. https://doi. org/10.1186/bf03353076

Omi T, Ogata Y, Hirata Y, Aihara K (2013) Forecasting large aftershocks within one day after the main shock. Sci Rep 3:2218. https://doi.org/10.1038/ srep02218

Reasenberg PA (1999) Foreshock occurrence before large earthquakes. J Geophys Res 104(B3):4755-4768. https://doi.org/10.1029/1998JB900089 
Scholz CH (1968) The frequency-magnitude relation of microfracturing in rock and its relation to earthquake. Bull Seismol Soc Am 58(1):399-415

$\mathrm{Scholz} \mathrm{CH}$ (2015) On the stress dependence of the earthquake b value. Geophys Res Lett 42(5):1399-1402. https://doi.org/10.1002/2014GL062863

Schorlemmer D, Wiemer S, Wyss M (2005) Variations in earthquake-size distribution across different stress regimes. Nature 437(7058):539-542. https:// doi.org/10.1038/nature04094

Schurr B, Asch G, Hainzl S, Bedford J, Hoechner A, Palo M, Wang R, Moreno M, Bartsch M, Zhang Y, Oncken O, Tilmann F, Dahm T, Victor P, Barrientos S, Vilotte JP (2014) Gradual unlocking of plate boundary controlled initiation of the 2014 lquique earthquake. Nature 512(7514):299-302. https:// doi.org/10.1038/nature13681

Shi Y, Bolt BA (1982) The standard error of the magnitude-frequency b-value. Bull Seismol Soc Am 72(5):1677-1687

Suyehiro S (1966) Difference between aftershocks and foreshocks in the relationship of magnitude to frequency of occurrence for the great Chilean earthquake of 1960. Bull Seismol Soc Am 56(1):185-200

Tamaribuchi K, Moriwaki K, Ueno H, Tsukada S (2016) Automatic hypocenter determination for the Seismological Bulletin of Japan using Bayesian estimation (in Japanese with English abstract). Quart J Seis 79:1-13

Tormann T, Enescu B, Woessner J, Wiemer S (2015) Randomness of megathrust earthquakes implied by rapid stress recovery after the Japan earthquake. Nat Geosci 8(2):152-158. https://doi.org/10.1038/ngeo2343

Tormann T, Wiemer S, Enescu B, Woessner I (2016) Normalized rupture potential for small and large earthquakes along the Pacific Plate off Japan. Geophys Res Lett 43(14):7468-7477. https://doi.org/10.1002/2016GL069309
Utsu T (1965) A method for determining the value of $b$ in a formula log $n=a-b M$ showing the magnitude-frequency relation for earthquakes (in Japanese). Geophys Bull Hokkaido Univ 13:99-103

Utsu T (1999) Representation and analysis of the earthquake size distribution: a historical review and some new approaches. Pure Appl Geophys 155(2-4):509-535

Wessel P, Smith WH, Scharroo R, Luis J, Wobbe F (2013) Generic mapping tools: improved version released. EOS Trans Am Geophys Union 94(45):409410. https://doi.org/10.1002/2013EO450001

Wiemer S, Wyss M (2000) Minimum magnitude of completeness in earthquake catalogs: examples from Alaska, the western United States, and Japan. Bull Seismol Soc Am 90(4):859-869

Woessner J, Wiemer S (2005) Assessing the quality of earthquake catalogues: estimating the magnitude of completeness and its uncertainty. Bull Seismol Soc Am 95(2):684-698. https://doi.org/10.1785/0120040007

Yoon CE, O'Reilly O, Bergen KJ, Beroza GC (2015) Earthquake detection through computationally efficient similarity search. Sci Adv 1(11):e1501057. https://doi.org/10.1126/sciadv.1501057

Zaliapin I, Ben-Zion Y (2013) Earthquake clusters in southern California I: identification and stability. J Geophys Res Solid Earth 118(6):2847-2864. https:// doi.org/10.1002/jgrb.50179

\section{Submit your manuscript to a SpringerOpen ${ }^{\odot}$ journal and benefit from:}

- Convenient online submission

- Rigorous peer review

- Open access: articles freely available online

- High visibility within the field

- Retaining the copyright to your article

Submit your next manuscript at $\boldsymbol{\nabla}$ springeropen.com 